REVISTA X, Curitiba, volume 14, n.4,p. 222-239, 2019

\title{
ATOS DE FALA SOBRE GÊNERO E SEXUALIDADE: A NECESSIDADE DO CONTRADISCURSO
}

Speech Acts About Gender And Sexuality: The Need Of Conter-Speech

\author{
Deleon BETIM - UEPG ${ }^{1}$ \\ Bernardo Ozorio IURK - UEPG ${ }^{2}$
}

\begin{abstract}
RESUMO: O presente texto objetiva realizar uma análise a partir da teoria dos atos de fala de J. L Austin sobre as questões de gênero e sexualidade, especificamente, a performatividade e a representação no que concerne à temática citada. Os exemplos aqui discutidos foram retirados das experiências vivenciadas e/ou observadas pelos pesquisadores em âmbitos familiares, escolares e esportivos. Foram selecionados devido sua alta incidência no cotidiano. Podemos observar que muitos atos de fala pretendem agir no sentido de manter o status quo e normatizar gêneros e sexualidades.
\end{abstract}

PALAVRAS-CHAVE: Atos de Fala; Performatividade; Gênero; Sexualidade.

\begin{abstract}
This work aims to study Speech Acts according to John L. Austin and other theorists of diverse areas on the issues of gender and sexuality. The examples discussed here were drawn from the situations expericied/observed by the researchers in family, school and sports environments. They were selected because of their high incidence in daily life. We can observe that many speech acts intend to act in the sense of maintaining the status quo and normalizing genders and sexualities.
\end{abstract}

KEYWORDS: Speech Acts; Performativity; Gender; Sexuality.

\section{PALAVRAS INICIAIS}

Este artigo tem como objetivo discutir atos de fala (AUSTIN, 1968) cuja repetição se dá incessantemente em espaços como a escola, a família, em âmbitos esportivos e também nas mídias sociais. Tais atos de fala apresentam estreitas relações com as incompreensões e desentendimentos no que diz respeito às questões de gêneros e sexualidades, confusões que se difundem cada vez mais, ironicamente, na dita era da "informação", Portanto, este texto surge na tentativa de denunciar e polemizar (no sentido de apresentar um contradiscurso ao status quo) certos ditos naturalizados em

\footnotetext{
${ }^{1}$ Professor do Departamento de Linguagem (UEPG), mestre em linguagem pela mesma instituição e especialista em gênero e diversidade (UFPR).

2 Mestrando no Programa de Pós-Graduação em Educação (UEPG), graduado em Licenciatura em Ciências Biológicas (UEPG). Contato: boyurk@ hotmail.com.

3 O conceito "era da informação" está intimamente ligado com o avanço da área da comunicação no ultimo quartel do século XX. (JUNIOR, 2015)
} 
nossa sociedade. Sobretudo, se faz uma escrita marcada pela angustia em que o presente momento político nos proporciona: um momento de retrocessos e o aumento significativo de violência seja verbal, física ou simbólica em nosso país.

Antes de trazer alguns conceitos teóricos e práticos que irão nortear o texto e nossas discussões, gostaríamos de reproduzir aqui um pequeno conto do escritor Alex Castro; podemos até dizer que se trata de um conto erótico:

\section{Três Jogos Inesquecíveis da Copa de 2006}

Brasil 1 x 0 Croácia - Terça-feira, 13 de junho de 2006, 16h Chefe nos libera às $14 \mathrm{~h}$. Almoço rápido, leve e apimentado no tailandês. (Não queremos nada indigesto.) "Bendito Kaká!”...

$\mathrm{Na}$ cama redonda, último capítulo do seriado favorito com laptop no colo: "Jack se sacrificou para salvar a Sydney, que lindo!" Beijo devagar e demorado na varanda, as ondas batendo lá embaixo.

"Um só gol nem é vantagem. E se a Croácia vira no segundo tempo?" No telefone: "Meu anjo, ainda estou aqui, acredita? Não liberaram a gente! Mal dá pra se concentrar no trabalho, só penso no jogo! Esse Brasil tá batendo um bolão!

***

Brasil 4 x 1 Japão - Quinta-feira, 22 de junho de 2006, 16h

Direto pra minha casa. Bolo de nozes, margaritas e húmus: açúcar pra energia, álcool pra relaxar, proteína pra força. "Caralho, Dida! Vai tomar gol do Jáspion?!"

Tentamos vestir as roupas de látex, mas o tesão estava demais e o talco de menos.

"Deixa eu ver o jogo! Se o Brasil perde do Japão, desisto dessa Copa!" No caminho até o quarto, tropeçamos, caímos, ficamos no sofá da sala, como adolescentes de hormônios borbulhantes.

"Êê, Ronaldo, demorô! Vamo, vamo, tem que fazer mais um!" Lambidas longas, loucas, lúdicas, lânguidas. "Juninhôôôôn! Graças a Deus! Pronto, pronto, agora relaxei."

Chupadas curtas, circulares, sinceras, suadas. "Santo Ronaldo! Quatro a um!!"

No telefone: "Estou acompanhando pela internet, fazer o quê, né? Emprego escroto. Mas que goleada linda, né, amor?! Estou aí do seu lado de coração."

$* * *$

Brasil 3 X Gana 0 - Terça, 26 de junho de 2006, meio-dia.

A empresa nos dá a tarde inteira livre. Almoço romântico no japonês, na mesa do fundo, para celebrar a vitória no jogo anterior: "Chupa, Japão." Em um shopping afastado, experimentamos sapatos e compramos livros, bebemos cachaça e tomamos sorvete.

"Não quer nem dar uma olhadinha no jogo?" Em casa, sessão de fotografia: sombrinha refletora e fundo desfocado, látex e couro, óleos e incensos.

"Pô, Gana? Vai ser o maior passeio." Depilamos nossas virilhas, deitamos agarradinhos. Gozamos uma, duas, três.

No telefone: "Isso é negócio de multinacional burra. Esses gringos não entendem a importância do futebol! Se o chefe fosse brasileiro, aposto que liberava todo mundo!" 
REVISTA X, Curitiba, volume 14, n.4,p. 222-239, 2019

No sábado, a França eliminou o Brasil e nossos planos para as semifinais foram abortados. Nunca mais nos vimos. Sempre teremos aquela Copa. (CASTRO, 2018)

Por que motivos trazer o conto para abrir este texto? Alguém poderia questionar e com certa razão. Explicamos: atuamos no ensino superior como docentes e já realizamos algumas experiências interessantes com base no conto lido. Se o alunado não desconfia quais as suas intenções ao apresentar o texto de Alex Castro numa aula qualquer ou curso, as interpretações podem revelar aquilo que muitas vezes nos negamos a ver, por mais evidente que seja. Falo da heteronormatividade compulsória (SEFFNER, 2013). Voltaremos a esse ponto posteriormente.

Ao questionar os alunos e alunas sobre o gênero dos personagens ou sobre as imagens que construíram ao ler a história, grande parte deles afirma imaginar um homem cuja relação se divide entre uma esposa e uma amante. No texto em questão, temos o foco da história na "suposta amante" e no "marido infiel" e a grande paixão que viveram. Os alunos falam sobre uma "família tradicional", "um homem padrão" após lerem as curtas passagens do envolvimento das duas pessoas.

Para além de qualquer moralismo ou qualquer padrão de comportamento, o conto que trazemos aqui não traz marcas de gênero (masculino ou feminino), ou qualquer referência à orientação sexual das personagens, isto é, não especifica se são homossexuais, bissexuais ou heterossexuais. Parece querer mostrar muito mais a conexão que as duas pessoas tiveram em um momento bem específico de suas vidas, do que qualquer outra questão. Logo, poderíamos ter como protagonistas dois homens, duas mulheres, homem e mulher, homem cis e mulher trans, homem trans e mulher cis, ou quaisquer outras combinações. Contudo, o que grande parte das pessoas leitoras imagina não foge muito daquilo que chamamos de heteronormativo. E as questões que vem logo em seguida são: o que isso nos ensina sobre nós mesmos? Sobre nossas mentalidades? Sobre os comportamentos e anseios que adquirimos ao longo de nossas vidas em sociedade? Para fazer alusão sobre as reflexões que o próprio autor do conto se propõe em realizar.

Na sequência, iremos discutir, pelo viés da Pragmática (ramo da Linguística) e da Linguística Aplicada, as questões de performatividade e representação no que concerne à temática de gêneros e sexualidade. Portanto, temos em mente que: "a Linguística Aplicada contemporânea é o envolvimento em uma reflexão contínua sobre si mesma: um campo que se repensa insistentemente" (PENNYCOOK, 2001, p. 171 
apud MOITA LOPES, 2008, p. 17). Além disso, sabemos também que trazer um estudo nesses termos é ter a interdisciplinaridade ${ }^{4}$ como elemento basilar e a noção de que conceitos e resultados precisam ser constantemente revistos.

Para nos dar apoio teórico fazemos uso de alguns teóricos como Butler (2003), Bourdieu (1999), Austin, (1965), entre outros. Por fim, faremos uma breve análise de alguns atos de fala que incidem em questões de gênero e sexualidade, com foco na parte da sexualidade, atos de fala já presenciados pelos autores tanto em âmbitos familiares, escolares e mesmo em âmbitos esportivos. Tais atos foram selecionados com base na frequência com que são usados e repetidos, o que garante certo status de discurso hegemônico $^{5}$, pois lançam raízes profundas sobre os pensamentos vigentes e sua historicidade. (PINTO, 2014).

\section{PERFORMATIVIDADE E ATOS DE FALA}

Como mencionamos anteriormente, vivemos em uma cultura fortemente marcada pela heteronormatividade. Ou seja, como o próprio termo sugere, significa que o regime vigente de sociedade considera uma norma apenas como natural e correta em detrimentos de outras. Tal norma articula as noções de gênero e sexualidade, "estabelecendo como natural certa coerência entre sexo (nasceu macho, nasceu fêmea), gênero (tornou-se homem, tornou-se mulher) e orientação sexual (se é um homem, irá manifestar interesse afetivo e sexual por mulheres, e vice-versa).” (SEFFNER, 2013, p. 150). Assim, o modelo heteronormativo faz com que as pessoas que não se encaixam em seus requisitos sejam entendidas como anormais. Pior que isso, faz com que muitas pessoas, devido à vigilância social e compulsória de gênero e sexualidade, omitam e não vivam suas vidas conforme suas identidades de gênero ${ }^{6}$ e seus desejos, tentando, dessa forma, se moldar conforme as dicotomias e binarismos de gênero e sexualidade considerados corretos e normais.

Por meio desse modelo de sociedade em que há um jeito "certo" de ser e agir e jeitos "errados" para serem detestados, reprimidos e perseguidos, seguimos em

\footnotetext{
4 Para os autores, interdisciplinar quer dizer que a partir de questões de estudo, o pesquisador pode buscar esclarecimentos e nortes em outras disciplinas. Por motivos de recorte não entraremos aqui em questões de transdisciplinaridade e de outras terminologias próximas.

${ }^{5}$ Com raízes no passado e muitas também no presente, esses discursos apresentam as características de serem muito repetidos e de apresentarem grande capacidade de controle de seus efeitos e de sua própria reprodução (PINTO, 2014, p. 60).

${ }^{6}$ Identidade de gênero, aqui, diz respeito à identificação da pessoa com algum gênero (masculino feminino ou híbrido). Lembrando que as noções de masculinidade e feminilidade não são um consenso em diferentes culturas. (JESUS, 2012)
} 
constante performatividade, em outras palavras, seguimos no âmbito do exercício da representação de comportamentos que são esperados. É importante pontuar que há certos contextos, para não dizer muitos, em que a convivência humana seria insustentável se não nos portássemos como seres que representam e fingem polidez e contentamento, mesmo que, em nossa intimidade, a vontade real fosse de sair correndo o mais rápido possível do ambiente. Imaginem, por exemplo, o mal estar que causaria participar de uma festa familiar e não cumprimentar ninguém e tampouco dar um sorriso para os presentes.

A performatividade que mencionamos anteriormente, já discutida por muitos teóricos renomados (BUTLER, 2003; BOURDIEU, 1999; AUSTIN, 1965, entre outros), é intrinsicamente discursiva. Conforme Austin (1965), a linguagem tem um caráter performativo. É por meio dela que realizamos nossos atos, isto é, agimos por meio da linguagem. Em relação à ficção podemos mencionar as palavras de Sartre (2004), que em seus escritos discute formas de literatura que se pretendem engajadas, também afirmando algo bastante similar quando diz que "falar é agir", atribuindo aos nossos enunciados (escritos ou falados) certos poderes de realizar ações nos meios em que atuamos. Dessa forma, por meio dos nossos atos de fala, para usar os termos de Austin (1965), podemos constranger, fazer promessas, criar expectativas, dar condolências, entre outras ações performativas, em suma, por meio da linguagem mudamos o cenário do qual fazemos parte.

De acordo com Austin (1965), dizer algo equivale a três atos simultâneos: o ato locutório, o ato ilocutório e o ato perlocutório. Grosso modo, o primeiro refere-se ao conteúdo linguístico; o segundo ao modo de dizer, a força proferida no ato e sua recepção; e o terceiro equivale aos efeitos causados no outro. É relevante ressaltar que todas essas três categorias pontuadas pelo autor estão intimamente relacionadas e ocorrem sem nenhuma separação evidente

Muniz (2010, p.101-102) ao dialogar com Butler (1997) traz a seguinte passagem:

[...] quando uma criança nasce e o médico profere o seguinte enunciado: 'é uma menina'!, não se trata apenas de falar qual é o sexo da criança, num ato puramente constativo; antes de tudo, é uma forma de se atribuir, desde já, à criança certa feminilidade, um gênero, ou seja, trata-se, antes, de um ato performativo e, por isso mesmo, político. (BUTLER, 1997 apud MUNIZ, 2010, p.101-102) 
Tais atos como "é uma menina", não são apenas constativos, como já dito, são, pois, antes de tudo, designações carregadas de historicidade. Ao verificar a genitália de um recém-nascido já se atribui para aquele individuo uma série de comprometimentos, perspectivas e comportamentos "inerentes" ao sexo.

Trazemos aqui alguns trechos da canção "Triste, louca ou má" da banda Francisco, el hombre, cuja letra pode ilustrar de uma maneira mais poética, porém melancólica, um pouco do que Butler expressa na citação acima e também clarear a discussão que estamos propondo:

Triste louca ou má/Será qualificada/Ela quem recusar/Seguir receita tal/A receita cultural/ Do marido, da família/ Cuida, cuida da rotina/ Só mesmo rejeita/Bem conhecida receita/ Quem não sem dores /Aceita que tudo deve mudar/ Que um homem não te define/Sua casa não te define/Sua carne não te define/Você é seu próprio lar/ Um homem não te define/Sua casa não te define/Sua carne não te define/ Eu sou meu próprio lar. (FRANCISCO, EL HOMBRE, 2016)

A letra traz que a bem conhecida receita só pode ser rejeitada por quem aceita (não sem dores) que tudo deve mudar. Que receita seria essa? Trata- se de uma receita histórica que vem sendo construída em diversas esferas. A canção retrata um contra discurso aos velhos costumes e a noção de destino único. É, pois, um discurso que reflete o momento histórico em que vivemos cuja noção de empoderamento e também a revisão de conceitos se tornam preponderantes. Conforme Carvalho (2015), percebemos que as relações de gênero acompanharam as mudanças decorrentes de acontecimentos que marcaram a história da humanidade como, por exemplo, a Revolução Industrial e a consolidação do capitalismo, além do processo de colonização que partiu da Europa no século XVIII.

Há uma divisão sexual do trabalho. Há uma construção de estereótipos a partir de certos costumes que vão se naturalizando nesses processos. Aos homens, atividades produtivas, o mercado de trabalho; às mulheres, atividades reprodutivas, trabalho doméstico. (CARVALHO, 2015) Atribuições dicotômicas associadas a este modelo formam, a nosso ver, a real "ideologia de gênero", na qual a mulher e o feminino são postos como inferiores e o homem e a masculinidade como superiores. Homens seriam racionais, objetivos, sem emoções. Mulheres, emotivas, submissas, do lar. "A partir destas demandas eles [os meninos] passam a ser socializados desde a infância e deles são cobradas atitudes condizentes com tais estereótipos em todas as instâncias da vida social" (CARVALHO, 2015, p.17). 
REVISTA X, Curitiba, volume 14, n.4,p. 222-239, 2019

Chamamos atenção para o excelente documentário The mask you live in (NEWSON, 2015), o qual mostra o quanto os estereótipos mencionados acima são nocivos não só para as mulheres, mas também para os homens. No mesmo documentário vemos que há uma crença muito forte de que homens e mulheres são fundamentalmente diferentes. No entanto, sabe-se que há grande diversidade de expressões de masculinidade e feminilidade e ambas têm diversos pontos de intersecções. Em suma, de acordo com os estudiosos que trazem suas pesquisas para o documentário, meninos e meninas são muito mais humanos em relação à suas vivências em sociedade (antes de ser a representação de um gênero exclusivamente) e, portanto, muito mais iguais do que diferentes. De acordo com testes psicológicos, homens e mulheres têm mais atributos em comum (cerca de $90 \%$ de características) do que divergências. Contudo, de forma geral, nos apegamos a esses $10 \%$ de convergências e em cima disso sustentamos os conhecidos estereótipos: Homens não choram, precisam demonstrar e ter força o tempo todo e são incentivados a violência; mulheres são dóceis o tempo todo, sentimentais e fracas.

Há graves consequências em entender as relações de gênero nesse patamar. Elas são tantas que não há espaço suficiente neste texto para se pensar em todas, mas iremos pontuar, de forma breve, alguns pontos.

Partindo do pressuposto de que a masculinidade é construída na rejeição de tudo que é feminino, devemos nos questionar: o que estamos ensinando para as nossas crianças sobre o que é ser homem e sobre o que é ser mulher? Se você quer começar uma briga entre meninos no parquinho, você pode fazer isso perguntando: quem deles é a "mulherzinha" ali? Já deixando subentendido que ser a mulherzinha significa ser o mais fraco, e eles irão se atacar dizendo uns aos outros quem é a "mulherzinha". Da mesma forma, se um treinador quer ofender o atleta, ela irá insinuar que o seu desempenho está como o de uma mulher. Infelizmente, tais atos de fala não são casos isolados e seus efeitos moldam o que entendemos sobre o que é "ser" e "agir" como homem ou como mulher. (NEWSON, 2015)

Notamos também que as características expansivas de meninos, crianças que eram abertas emocionalmente, tendem a ser minimizadas fortemente, sobretudo, na adolescência. A linguagem muda, as relações de amizade também. Os meninos se fecham e são condicionados a não se expressarem ou demonstrarem sentimentos. É possível compreender tal mudança se visualizarmos que há uma vigilância social determinante para que isso aconteça, seja na própria casa, na escola, ou mesmo em 
outros ambientes como os contextos de esporte, por exemplo. A grande questão é que quando a linguagem emotiva desaparece, a taxa de depressão, suicídio ou mesmo a fuga em bebidas e drogas aumentam em grande escala. (NEWSON, 2015)

Outro ponto preocupante: por que o fator gênero quase não é mencionado ou levado em consideração nos casos de homicídios? Por que as meninas não saem por aí fazendo tiroteios? De acordo com os dados apresentados no documentário, 90\% dos responsáveis por homicídios são homens e quase $50 \%$ têm menos de 25 anos. Além disso, 94\% dos homicídios em massa são causados por homens (NEWSON, 2015).

Portanto, devemos pensar nas relações entre essa "ideologia de gênero" (aqui entendida como o sistema heteronormativo, dicotômico e estereotipado das noções de gênero e sexualidade) e as consequências violentas de opressão que já há algum tempo estamos presenciando. Isto é, reiterando a questão: o que estamos ensinando para as nossas crianças sobre o que é ser mulher e sobre o que é ser homem? O que ensinamos sobre igualdade e respeito frente à diversidade que cada vez mais ganha evidência e força? Como isso influencia nos agravantes de desigualdades e violências? A nosso ver, são questões de urgência. Além disso, a mensagem que Newson (2015) deixa é a de que homens têm que ser parte da luta por igualdade, seja entendendo privilégios e as construções estruturantes das relações de poder (FOUCAULT, 1988), seja combatendo estereótipos e violências, de forma a permitir-se uma vivência mais autêntica em seus cotidianos e relações.

Bourdieu (1999) traz o conceito de violência simbólica, bastante relevante para este artigo. Nas palavras do autor: "É uma violência suave, que se exerce essencialmente pelas vias puramente simbólicas da comunicação e do conhecimento, ou, mais precisamente do desconhecimento, do reconhecimento ou, em ultima instância, do sentimento.” (BOURDIEU, 1999, p. 7). No entendimento de Bourdieu (1999), tal violência simbólica ocorre quando existe uma relação de dominação que não é questionada. Atualmente, cada vez mais, toda a problemática que trazemos aqui é motivo de discussão e contestação e, embora algumas estruturas estejam em mudança, ainda há um longo caminho a se percorrer.

Ao observar atos de fala (para usar a terminologia cunhada por Austin, 1965) que são constantemente reiterados em diferentes âmbitos (escola, casa, mídia, centros esportivos etc.), muitas vezes perpassados por violência simbólica, selecionamos alguns deles a fim de refletir sobre seus efeitos e incoerências. 
Vale ressaltar que tais atos dizem respeito mais às questões de sexualidade do que às questões de gênero propriamente, no entanto, tal separação não é muito palpável e simples como se pensa, pois em muitos momentos esses dois temas são tomados por intersecções e influências. Ainda assim, é relevante "não tomar o termo gênero como significando sexualidade, embora a literatura da área mostre que são conceitos indissociáveis, do ponto de vista de sua proximidade, porém não se constituem como sinônimos" (ALBANO, 2006, p.8).

Nosso recorte se justifica pelas vivências dos autores deste trabalho que trazem mais experiências quanto a questão de sexualidade, do que em relação às questões de gênero propriamente (fortemente vinculada às lutas feministas). Isso não significa, de modo algum, que o segundo ponto não tenha impacto em nossas ações e escolhas teóricas, como pode ser comprovado pelas reflexões que estamos compartilhando neste texto. Desta forma, iremos pontuar de forma mais atenta como entendemos os conceitos supracitados. É relevante pontuar que ainda não um consenso entre eles, mesmo entre os estudiosos da área.

Pelo viés que discutimos, falar de gênero é falar de expressão individual e coletiva, das relações entre homens e mulheres (cis ou trans), é pensar também na constituição da identidade de uma pessoa dentro de suas possibilidades performativas ${ }^{7}$ (identidade que não é fixa, mas plural e mutável, de acordo com Hall (2005)).

Contudo, como já apontado em outro momento (BETIM; ARAUJO, 2016, p. 39), Butler (2003) problematiza a noção de construção social e cultural de gênero estabelecida por algumas correntes. A autora alerta que se a biologia é por vezes interpretada como determinista, por outro lado, a cultura também pode ocupar esse papel (pensando nas correntes que apagam o processo de construção e tratam os corpos como "recipientes passivos de uma lei cultural inexorável"). Isto é, ir de um extremo a outro não seria plausível para as discussões mais sérias sobre gênero e diversidade.

A mesma autora ainda diz que: "se o gênero e o sexo são fixos ou livres, é função de um discurso que [...] busca estabelecer certos limites à análise ou salvaguardar certos dogmas do humanismo como um pressuposto de qualquer análise de gênero" (BUTLER, 2003, p.27). Isto é, coloca-se em debate que as discussões sobre

\footnotetext{
7 “O que importa, com relação à transexualidade, é que ela não é uma benção nem uma maldição, é mais uma identidade de gênero, como ser cissexual. Nesse sentido, a resposta mais simples e completa para definir as pessoas transexuais poderia ser a de que: Mulher transexual é toda pessoa que reivindica o reconhecimento social e legal como mulher. Homem transexual é toda pessoa que reivindica o reconhecimento social e legal como homem." (JESUS, 2002, p.15)
} 
gênero são discursivamente estabelecidas dentro dos limites ou enquadramentos de uma cultura hegemônica, sendo essas fronteiras discursivamente marcadas por estruturas binárias. Portanto, vale atentar para aquilo que pode ou não pode ser mobilizado dentro dos meandros culturais vigentes. Tal discussão foi iniciada por Foucault (1988) que aponta, entre outros fatores, como o poder e os discursos estão vinculados por meio de instituições que regulam e repreendem os atos sociais, como por exemplo, igrejas, escolas, famílias, o próprio campo da medicina etc.

Já a sexualidade, de forma simples, pode ser entendida como os desejos e afetos que as pessoas sentem umas pelas outras (SANTOS; ARAUJO, 2009). Podemos pensar (num primeiro momento) em heterossexualidade, homossexualidade e bissexualidade. No entanto, vale lembrar que os conceitos que trazemos aqui são perpassados por crenças, costumes, tabus, questões culturais e econômicas, entre outros fatores e são entendidas de maneiras distintas ao longo do tempo. Conforme atesta Faria (1998)

O estudo de outras culturas, a partir da antropologia e da história, foi mostrando as diversas mudanças de um momento para outro, de um povo para outro e também as diferenças dentro de uma mesma cultura. Mostrou também que as relações pessoais, a família e o sexo são elementos construídos de acordo com a economia, o tipo de trabalho, a tecnologia, a religião e a ciência. (FARIA, 1998, p. 11)

Outro ponto importante, pensando mais especificamente nas questões de educação, como pontua Louro (2007), é que mesmo que não haja uma discussão profícua sobre sexualidade na escola, ou uma disciplina que atenda ao tema, ela (a sexualidade) está na escola, como está em outros ambientes, porque faz parte dos sujeitos, não podendo ser "desligada" como se fosse algo que pudéssemos tirar de nós mesmos, uma vez que a presença da sexualidade independe da intenção de se falar sobre ela explicitamente. Nesse sentido:

[...] é preciso considerar que "a sexualidade é uma das dimensões do ser humano que envolve gênero, identidade sexual, orientação sexual, erotismo, envolvimento emocional, amor e reprodução" (CASTRO; ABRAMOVAY; SILVA, 2004) e, portanto, não pode ser alienada das características humanas. (SANTOS; ARAUJO, 2009, p.16)

Por isso, entendemos que quando as pessoas insistem em certas falas e discursos, elas estão colaborando com os enquadramentos vigentes. Isto é, as ações (re)produzidas em sociedade geram o efeito de regular corpos, comportamentos, representações e desejos. 
REVISTA X, Curitiba, volume 14, n.4,p. 222-239, 2019

Vejamos os atos de fala que selecionamos para uma breve análise (ao lado de cada ato de fala pontuamos breves comentários sobre o tipo de ação que tal ato intenciona ao ser enunciado):

“Você não é viado, né?" (Ideia de correção, de categorizar e diferenciar o normal do anormal)

Como atesta Auad (2004), para o menino que é muito calado, a ele pode-se atribuir algum traço patológico. A autora realizou sua pesquisa em contexto escolar e verificou que para os meninos que não participam do que é considerado um comportamento típico de menino na escola, isto é, falar alto, fazer algazarra, chamar atenção etc, a eles restam alguns olhares vigilantes e desconfiados.

$\mathrm{O}$ ato de fala acima remonta a experiências dos autores deste texto em âmbitos esportivos. Retrata um menino que, embora junto com um grupo maior de meninos, não participa das brincadeiras feitas pelos demais. A pergunta é feita na negativa, mostrando que o "ser viado" é algo não bem visto pelo grupo. Tal atitude coloca o menino que não compactua com os comportamentos dos demais no dilema de ou se adaptar e tornar- se um igual, ou destoar e não mais pertencer ao grupo maior.

$\mathrm{O}$ ato de fala acima não é, explicitamente, uma afirmação sobre a realidade (verdadeira ou falsa), mas sim uma pergunta. Portanto, é um ato ilocucionário, isto é, que traz uma força e intenção. (AUSTIN, 1965).

"Quem tá ganhando? Dois a zero para o time masculino." (Relaciona o time perdedor como o mais fraco e implicitamente com a ideia de feminino - brincando ironicamente com o binarismo masculino $\mathrm{x}$ feminino, sendo que o segundo é posto como algo negativo, menor e vexatório.)

Seguindo o mesmo ritmo do primeiro ato de fala. O segundo que trazemos é constantemente repetido em âmbitos esportivos, onde equipes masculinas disputam vitórias. Quando se quer saber o placar do jogo, possivelmente ao time que esteja perdendo será atribuída a ideia de feminino (explicita ou implicitamente), como sendo um polo naturalmente fraco e menor. Este ponto é bastante debatido no documentário supracitado: The mask you live in (NEWSON, 2015).

Ao diferenciar constatativos e performativos, Austin criou uma dicotomia que, mais tarde, ele mesmo iria questionar. Segundo Filho (2006, p. 224) são os constatativos 
usados para "descrever fatos e eventos" e os performativos, as "sentenças que são usadas para realizar (to perform) algo, e não para descrever ou relatar."

Um exemplo de constatativo típico é "Maria está brincando na praça" e, de performativo, "Prometo que lhe pagarei amanhã". Enquanto constatativos podem ser verdadeiros ou falsos em relação aos fatos que descrevem, um performativo não é realmente nem verdadeiro nem falso, uma vez que não descreve um fato, mas deve ser considerado como bem ou mal sucedido, dependendo das circunstâncias e consequiências da realização do ato. (FILHO, 2006, p.224)

Contudo, quanto ao enunciado: Dois a zero para o time masculino. Não se trata apenas de uma descrição (falsa e irônica de uma partida esportiva), é também um ato performativo, pois reverbera uma ação; um entendimento de como a sociedade deve ser, ou como deve se organizar. (Voltaremos nesse ponto adiante).

"Fulano tem filho pequeno. Um dia ainda vai pagar com a língua" (ideia de sexualidade como castigo)

Aqui temos algo que consideramos particularmente problemático em âmbitos familiares, quando surge a discussão das sexualidades. Sobretudo se há famílias mais tradicionais que demonstram aversão a outras formas de amor/desejo sexual. Fala-se dessas famílias mais conservadoras, quando há crianças pequenas, que um dia irão "pagar com a língua" por seus preconceitos, isto é, que poderão ter filhos ou filhas homossexuais. Contudo, o que tal presságio demonstra é que ter um filho ou filha gay seria algum tipo de castigo ou punição. No entanto, o real castigado, a nosso ver, será o filho ou filha que por ventura tenha uma orientação sexual que não a esperada pelos pais, porque, provavelmente, não terá apoio familiar para se entender como sujeito gay, lésbica ou bissexual - sem mencionar questões de identidade de gênero que começam a ganhar visibilidade muito recentemente. Esse pensamento de castigo tem uma historicidade marcada nas lutas e resistências da população LGBTQ+ ${ }^{8}$; destacamos os primeiros casos de AIDS na década de 1980 e 1990, que por influência dos preceitos cristãos, foram erroneamente concebidos como "castigo de Deus" ou um "câncer gay". (BRITO; ROSA, 2018).

Ademais, há claramente um ato ilocucionário que performa uma promessa. A promessa de castigo. Ao conjugar as crenças populares e religiosas, mais a

\footnotetext{
${ }^{8}$ LGBTQ+ (lésbicas, gays, bissexuais, travestis e transexuais, queer e o + ampliando o espectro de gênero e sexualidade para as modalidades novas que as letras não dão conta de descrever)
} 
REVISTA X, Curitiba, volume 14, n.4,p. 222-239, 2019

historicidade do movimento LGBTQ+, podemos perceber que um enunciado como o que está em discussão aqui não é um fala isolada, portanto, traz consigo um aspecto ritualizado, fator importante para a força elocucionária. (AUSTIN, 1965)

“Nossa, eu amo os gays! Só não concordo com a prática” (Separar o pecado do pecador. Homofobia cordial)

"Deus acolhe a todos, mas ele foi muito claro quando criou o homem e a mulher" (Pensamento tradicional embasado no enquadramento do binarismo homem e mulher, ideia de "conservar a família tradicional cristã" dos "pecados" do mundo)

No mesmo sentido, temos os dois atos de fala anteriores, os quais são embasados fortemente pelas instituições religiosas. Ambos têm uma tradição vinda do cristianismo medieval, uma espécie de regra: odiar o pecado e amar o pecador (KARNAL, 2012). Entendemos o primeiro ato de fala como um tipo de homofobia cordial, bastante comum ainda nos dias de hoje. Já o segundo, reverbera por questões mais profundas de crenças e tradições. Ambos disseminam fortemente preconceitos e falácias.

Vale pensar ainda sobre o segundo ato de fala. Estamos falando sobre o Deus de quem? Os deuses do candomblé? Os deuses do povo Guarani? Podemos questionar também: "é bom um deus que desafia um pai a matar o próprio filho para demonstrar que ama a deus? É bom um deus que pune e põe no inferno? Que critério é esse?" (BRITTO, 2002 p. 142). Não queremos negar a legitimidade de nenhuma religião com os nossos questionamentos, no entanto, queremos lembrar que há muitas representações religiosas no país e no mundo e cada uma segue preceitos ideológicos diferentes, não sendo um consenso nem mesmo a ideia de deus. Portanto é precipitado e inócuo tomar dogmas pessoais como universais e pensar que podem servir de regra para todas as pessoas do mundo.

Aqui também temos enunciados com aparência de constatativos: "Deus criou o homem e a mulher. Ela ama os gays." Independente se verdadeiros ou falsos, descrevem situações e sentimentos. Contudo, como bem pontua Filho, (2006, p.224):

Austin logo percebeu que [a dicotomia constatativos $\mathrm{x}$ performativos] era inadequada, uma vez que o constatativo tem também uma dimensão performativa, isto é, descrever é também um ato que realizamos e pode ser bem ou mal sucedido; assim como os performativos têm uma dimensão constatativa, já que mantêm uma relação com um fato. (FILHO, 2006, p.224) 
Em sentido semelhante, Pinto (2002) colabora com a afirmação acima:

Austin afirmou que as estruturas linguísticas características dos enunciados performativos não operam por si sós; elas necessitam de um contexto, de convenções ritualizadas para realizarem seu efeito. É num contexto determinado que um/a falante emite o enunciado cujo significado repousa na ação que ele produz. Isso significa que as condições do ato de fala, e não sua fórmula em palavras, que operam o performativo; o que leva à conclusão de que qualquer sequência [...] é um enunciado performativo. (PINTO, 2002, p.103).

Daí nosso entendimento de que nenhum ato de fala é produzido de forma neutra, sem pretensões. Vejamos os dois últimos enunciados que iremos debater: Ambos ocorrem de forma ritualizada, carregados de intencionalidade para que realizem o efeito de manter a comunidade LGBTQ+ à margem das representações positivas.

"Não sou contra gays, mas precisamos proteger nossas crianças" (Relaciona a homossexualidade com algo ruim, que precisa ser evitado)

Quando dizem por aí que querem proteger as crianças de qualquer influência ou conhecimento sobre as questões LGBTQ+, isso encobre preconceitos dos mais perversos. Não podemos dizer ao certo com quais intenções performativas tal ato de fala é proferido, mas podemos cogitar algumas interpretações: a) Crença de que há uma forte relação entre a homossexualidade e a pedofilia; b) Crença de que a homossexualidade é algo que se pega, como uma doença, ao ter contato com gays; c) Crença de que gays não devem ter contato com crianças, por motivos diversos, mas, sobretudo, por não serem boas influências, ou por serem necessariamente pessoas odiosas.

Por definição, crença é um ato de fé de origem inconsciente; é uma afirmação que não dialoga com o pensamento crítico. Uma crença não precisa de argumentos lógicos ou embasamento para existir (LE BON, 2002). Portanto, não precisamos pontuar que todas as crenças anteriores não se sustentam por vias lógicas.

"Você nem parece gay/ bil lésbica/ trans" (Normatizar a vivência LGBTQ+. Enquadrar em padrões heteronormativos)

Por fim, a ideia errônea de que para ser LGBTQ+ é preciso parecer um. Questionamos, então, o que é parecer gay? Parecer trans? Será que esperam que a comunidade ande por aí no seu dia a dia com uma bandeira de arco íris nas costas? Em tempo, ressaltamos que não há apenas um jeito de ser gay ou de ser lésbica ou bi ou 
trans... Antes de sermos rotulados pelas orientações ou pelas identidades de gênero, somos humanos diversificados como qualquer outro. Além disso, tal ideia mascara um forte preconceito arraigado na sociedade: "tudo bem ser gay, você só não precisa parecer um". Pois bem, sabemos que quem mais "aparenta" ser gay, no caso de homens, são, quase sempre, os afeminados, algo que também é questionável, pois ser afeminado não diz respeito necessariamente à orientação sexual do sujeito. Então voltamos a uma questão de gênero já debatida anteriormente: Somos ensinados e ensinamos as nossas crianças que o feminino é algo ruim, menor e fraco, logo, ser gay e afeminado é um duplo peso para a pessoa. "Não basta a vergonha de ser gay, ainda tem que ser afeminado", pensam os preconceituosos. Isso justifica em boa parte o porquê de gays afeminados serem os que mais sofrem ataques e represálias em nosso país, juntamente com as pessoas trans, sendo as que mais sofrem violência de todos os tipos, inclusive as fatais. O Brasil é o país que mais mata travestis e transexuais no mundo9 .

Não podemos amenizar o peso das informações trazidas aqui ou fingir que não é com o nosso povo, que não seres humanos. Portanto, este texto, antes de ser um artigo científico, é um ato de fala político e performativo. É a tentativa um pouco pretensiosa de agir nos espaços, mesmo que de forma lenta e reduzida. É a esperança de visualizar ações por justiça e igualdade entre todas as pessoas.

\section{PALAVRAS FINAIS}

O objetivo desta pesquisa foi o de desconstruir ideias arraigadas na sociedade, muitas vezes estereotipadas, sobre as questões de gênero e sexualidade. Nossa linha de pesquisa segue os preceitos da Linguística Aplicada, mais especificamente da Pragmática, sobretudo a teoria dos atos de fala de Austin, (1965), no entanto, dialogamos evidentemente com outras áreas e linhas próximas.

Verificamos que há uma série de crenças e falácias sustentadas dentro de um sistema hegemônico de valores, as quais são reproduzidas discursivamente em atos de fala com a intenção de manter o status quo. Isto é, o de dizer que mulheres são naturalmente inferiores e de que a comunidade LGBTQ+ deve ficar no armário e não incomodar a família cristã e a sociedade "normal". Tais discursos revelam o quanto a comunidade é posta numa categoria de abjeção.

\footnotetext{
${ }^{9}$ Informação retirada do site:< http://g1.globo.com/profissao-reporter/noticia/2017/04/brasil-e-o-pais-quemais-mata-travestis-e-transexuais-no-mundo-diz-pesquisa.html>. Acesso em 10 nov. 2018.
} 
REVISTA X, Curitiba, volume 14, n.4,p. 222-239, 2019

Pudemos notar também que os atos de fala com aparência de constatativos, são também performativos (Conforme as próprias reflexões de Austin). Sendo assim, a sua performatividade será bem sucedida a depender das convenções ritualizadas e também da intencionalidade do ato. Isto é, as escolhas das palavras e os enunciados só farão sentido se forem autorizados e reconhecidos pelos participantes de um determinado contexto.

Nesse sentido, é preocupante pensar que os atos de fala que verificamos neste artigo não são ações isoladas, muito pelo contrário, só estão aqui devido a sua alta frequência de reprodução nos mais diferentes âmbitos, como já mencionamos a própria escola, ambientes familiares, ambientes esportivos, dentre outros. A característica de reprodução fácil e de não ser algo isolado é fundamental para se ter um sistema estruturante de valores regido por preconceitos e desigualdades, daí vem a força elocucionária discutida por Austin (1965). Portanto, reiteramos, como palavras finais, a importância do contradiscurso, o qual foi o nosso maior anseio aqui.

\section{REFERÊNCIAS}

AUAD, Daniela. Relações de gênero nas práticas escolares e a construção de um projeto de co-educação. In: $27^{a}$ Reunião Anual da Anped. 2004, Caxambu, MG. Anais da 27 Reunião Anual da Anped. 2004, p. 01-17.

AUSTIN, J.L. How to do things with words. New York: New York Press, 1965.

BETIM, D.; ARAUJO, R. K. de. Gênero e diversidade sexual: com a palavra, professoras de Carambeí- PR. In: POLIDORO, M.; CANAVESE, D. (Orgs.). Educação a distância, gênero e diversidade: Interações nas práticas escolares. Rio de Janeiro: Autografia, 2016, p. 32-46.

BOURDIEU, P. A dominação masculina. Rio de Janeiro. Bertrand Brasil, 1999.

BRITO, F.L.C.B.; ROSA, J.M. "OS LEPROSOS DOS ANOS 80”, "CÂNCER GAY”, "CASTIGO DE DEUS": homossexualidade, AIDS e capturas sociais no Brasil dos anos 1980 e 1990. Revista Observatório, Palmas, v. 4, n. 1 p. 751 - 778, jan -mar. 2018

BRITTO, L. P. L. Língua e ideologia: a reprodução do preconceito. In: BAGNO, M. (Org.), Linguística da norma. São Paulo: Edições Loyola, 2002, p. 135-154.

BUTLER, J. Problemas de gênero. Feminismo como subversão da identidade. Tradução de Renato Aguiar. Rio de Janeiro: Civilização Brasileira, 2003.

CASTRO, A. Três Jogos Inesquecíveis da Copa de 2006. Disponível em: $<$ https://www.uol/copadomundo/especiais/copa-brasileira-de-letras-2006-alexcastro.htm\#tres-jogos-inesqueciveis-da-copa-de-2006> Acesso em 10 nov. 2018. 
CARVALHO, M. G. A dicotomia masculino x feminino na construção do gênero e suas implicações sociais. In: Educação e diversidade: a questão de gênero e suas múltiplas expressões. COVOLAN, N.T; OLIVEIRA, D.C. (Orgs.). Rio de Janeiro: Editora Autografia, 2015, p. 15-25.

FARIA, Nalu. Sexualidade e gênero: uma abordagem feminista. In: FARIA, Nalu (Org.) Sexualidade e Gênero - Cadernos Sempreviva. São Paulo: Sempreviva Organização Feminista, 1998.

FILHO, D. M. S. A teoria dos Atos de Fala como concepção pragmática de linguagem. Filosofia Unisinos, p. 217-230, 2006

FOUCAULT, M. História da sexualidade 1. A vontade de saber. 19. edição. Rio de Janeiro. Graal, 1988.

HALL, S. A identidade cultural na pós-modernidade. 10. ed. Rio de Janeiro: DP\&A, 2005.

HOMBRE, F. Triste, Louca ou Má. 2016. Disponível em: $<\mathrm{https}$ ://www.youtube.com/watch?v=lKmYTHgBNoE>. Acesso em 20 nov, 2018.

JESUS, J. G. de. Orientações sobre identidade de gênero : conceitos e termos / Brasília, 2012. 42p.

JUNIOR, L. R. Aspectos sobre a era da informação, o direito eletrônico e a horizontalidade global dos direitos. Caicó: UFRN, 2015. 58f. Monografia Bacharelado em Direito - Universidade Federal do Rio Grande do Norte.

LE BON, G. As Opiniões e as Crenças. Tradução de Antonio Roberto Bertelli. São Paulo: Ícone, 2002. [Disponível em: <http://www.ebooksbrasil.org/eLibris/lebon.html> (Acesso em 20 out. 2018)

LOURO, G.L. Gênero, sexualidade e educação: uma perspectiva pós-estruturalista. 8. ed. Petrópolis. Vozes, 2007

SANTOS, D.B.C.; ARAUJO, D.C. Sexualidade e Gêneros: Questões Introdutórias. PARANÁ, Secretaria de Estado da Educação. Departamento da Diversidade. Núcleo de Gênero e Diversidade Sexual. Sexualidade. Curitiba: SEED, 2009, p.13-27

SARTRE, Jean-Paul. Que é a literatura? 3. ed. Tradução de Carlos Felipe Moisés. São Paulo: Ática, 2004.

SEFFNER, F. Sigam-me os bons: apuros e aflições nos enfrentamentos ao regime da heteronormatividade no espaço escolar. Educ. Pesqui., São Paulo, v. 39, n. 1, p. 145159, jan./mar. 2013.

KARNAL, L. Conversas com um jovem professor. 2. ed. São Paulo: Contexto, 2017.

MOITA LOPES, L.P de. Uma Linguística Aplicada Mestiça e Ideológica: Interrogando o campo como linguista aplicado. In: MOITA LOPES, Luiz Paulo. (Org.). Por uma linguística aplicada Indisciplinar. São Paulo: Parábola Editorial, 2. ed. 2008, p. 13-42 
REVISTA X, Curitiba, volume 14, n.4,p. 222-239, 2019

MUNIZ, Kassandra. Sobre Política Lingüística ou Política na Lingüística: identificação Estratégica e Negritude. In: FREITAS, Alice Cunha (Org.). Linguagem e exclusão. Uberlândia: EDUFU, 2010, p. 99-123.

THE MASK you live in. Direção: NEWSON, J.S. et al. Estados Unidos: Netflix, 2015. $97 \mathrm{~min}$.

PINTO, J. P. Performatividade radical: ato de fala ou ato de corpo? Revista Gênero, Niterói, v.3, n.1, p.101-110, 2002.

Hegemonias, contradições e desafios em discursos sobre língua no Brasil. In: CORREA, D. (Org.). Política linguística e ensino de língua. São Paulo: Pontes, 2014, p. 59-72. 